\title{
The Role of Critical Strategic Planning Factors in Enhancing Marketing Prowess
}

\author{
Sawsan Ibrahim Rajab and Majeed Hamid Majeed, \\ \{dr_sawsanibrahimrajab@ntu.edu'1.iq, dr.majeed@ntu.edu.iq $\left.{ }^{2}\right\}$ \\ ${ }^{1}$ Kirkuk Technical Institute, Northern Technical University \\ ${ }^{2}$ Assist. Prof. Dr. Administrative Technical College, Northern Technical University
}

\begin{abstract}
The study seeks to identify critical strategic planning factors (strategic direction, strategic thinking, strategic analysis, and strategic flexibility) and their role in promoting marketing excellence in the KRUNGI Group of Companies in Kirkuk Governorate. To study its objectives, a questionnaire was consistent with the design of the study data and was distributed to the intentional sample. Which we hope will be useful for the group of companies surveyed, and their counterparts from similar companies.
\end{abstract}

Keywords: Critical strategic planning factors, strategic direction, strategic thinking, strategic analysis, strategic flexibility, marketing excellence.

\section{Introduction}

Resources of all kinds are the artery of the organization, which provides it with all the requirements necessary for its survival, continuity, growth and the organization if it wants to stay actively and positively in the market to use its resources efficiently; efficiently enable it to achieve its objectives, and maintain its market share, and its position through development, innovation, and innovation In presenting a new and distinctive, which maintains its position in a market that contains many of its competing organizations that work in the same field and can offer the same or alternative products and efficiently may be better and higher than their products. Accordingly, there is an urgent need to develop more than one strategy that enables the organization to achieve its objectives in the light of its resources in a changing environment; strategies that determine the options available to the organization through the interaction of its strengths and weaknesses, with the opportunities and threats expected in the environment that can be managed through wise management It contributes to enhancing its marketing prowess, which will surely give a higher value to the organization making it irreversible.

Based on this, the study seeks to demonstrate the role of critical strategic planning factors in enhancing the marketing prowess of the KRG Group in Kirkuk governorate, its importance to decision-makers in diagnosing barriers and determinants, as well as incentives and positives that they can face when formulating and then taking decisions, which affect directly in upgrading all activities and operations, including marketing in particular. 


\section{The methodology of the study}

\subsection{The problem of the study}

The problem of the study revolves around critical strategic planning factors and their role in enhancing marketing excellence. To answer this problem, the following questions have been formulated, which we hope will enable us to reach logical explanations. These questions are as follows:

1. What are the critical strategic planning factors?

2. Is there a role for these factors in enhancing the marketing prowess of the group of companies Krkonji in the province of Kirkuk?

\subsection{The importance of the study}

The importance of the study is reflected in the attempt to identify each of the critical strategic planning factors, and its role in promoting marketing excellence in general, and the group of companies Alkronji in particular, which we target to study and analysis, as well as the following:

1. The role of critical strategic planning factors in marketing excellence in terms of relevance and impact.

2. Provide information to the researched group in a way that enables them to understand the role of critical strategic planning factors in enhancing their marketing prowess, which is positively reflected in presenting a positive image of their products not only in Kirkuk governorate but also in the Iraqi market and the region in general.

\subsection{Objectives of the study}

The objectives of the study can be summarized as follows:

1. Enriching the cognitive side by providing a theoretical framework that examines the variables of this study, based on the overflowing of relevant literature.

2. Identify critical strategic planning factors and indicate their role in enhancing marketing excellence.

3. Present a set of proposals in the light of the conclusions of the study; which we hope will be feasible for the research group.

\subsection{The study hypothesis}

The research is based on two main hypotheses:

The first main hypothesis: Critical strategic planning factors at the macro level are significantly related to marketing excellence.

The following hypotheses are subdivided:

The first sub-hypothesis: the strategic direction is related morally to marketing excellence. The second sub-hypothesis: strategic thinking is linked morally to marketing excellence.

The third sub-hypothesis: Strategic analysis is correlated significantly with marketing excellence.

The fourth sub-hypothesis: strategic flexibility is related to marketing excellence.

The second main hypothesis: Critical strategic planning factors and macro-level significantly affect marketing excellence.

The following hypotheses are subdivided:

The first sub-hypothesis: the strategic direction significantly affects marketing excellence. The second sub-hypothesis: strategic thinking significantly affects marketing prowess. 
The third sub-hypothesis: Strategic analysis significantly affects marketing prowess.

The fourth Sub-hypothesis: Strategic flexibility significantly affects marketing prowess.

\subsection{Study methodology and method of collecting data and information}

Depending on many Arab and foreign sources to obtain the data and information necessary to build the research in theory, as for the field side has been using the questionnaire form, which is one of the appropriate tools for data collection, for this purpose a questionnaire was prepared following the requirements of the research, and contribute to the provision of data adequate and can be used in the statistical analysis.

\subsection{Society and sample study}

The Karunji group of companies in Kirkuk governorate represents the population of the study. The sample of the study was adopted by a deliberate sample, which included the Board of directors, the directors of laboratories, the heads of the main departments, and the production lines in the researched group. The number of members of the study population (50), representing the members of the sample approved for research and analysis, has been adopted this group of workers in the group because of their role in setting goals, and building plans to achieve them, and their ability to make and make decisions, organize work and guide Employees are motivated to achieve the highest levels of performance to ensure that the group distinguishes itself from similar organizations in terms of activity and products. Based on this, (50) questionnaires were distributed, fully retrieved, and valid for analysis only (43) questionnaires. The Liker scale was adopted to measure the responses of the two respondents. Which starts with (strongly agree, agree, agree to some extent, do not agree, do not agree strongly), and assigned each option of the above answers grades starting with $(5,4,3,2,1)$, as given the highest degree of option agreed heavily passing through to other options.

\section{The Theoretical Framework}

\subsection{Critical Strategic Planning Factors}

\subsection{1 critical success factors}

Critical Strategic Planning Factors defined by (Marais, et al) as "areas, characteristics, activities, variables, and strategic elements of high importance; affect the success of the organization and its employees, and therefore the management of the organization works to It gives special attention to the fact that it is the separation between the profit and the loss of the organization in certain circumstances. Critical factors vary from organization to organization. The management of the organization determines the most influential factors in its performance, and therefore the factors that directly contribute to its success or failure, as well as identifying these factors ensure the organization to diagnose each of the opportunities that can be provided by the work environment They can be used wisely to generate high returns for the organization and to avoid risks and threats that can burden the organization with losses that the management of the organization does not want.

Based on this we see that the success factors are [1]. attributes, characteristics, and qualities that characterize the internal and external environment of the organization have a high impact 
on the work of the organization and its activities and thus achieve its objectives, they are necessary to accomplish the tasks, and therefore can be counted the keys adopted by the organization in ensuring performance-oriented. These factors vary according to different organizations, in terms of size, activity, goals, and work style, as well as other factors and variables that can distinguish an organization from another in the same work environment. Critical factors are critical for business organizations, particularly when opportunities arise for them to be distinguished and uniquely, therefore the management of the organization should be careful in determining the critical factors affecting Direct action and its future, which should meet several conditions and controls, which are as follows: [2]

1. Importance: To include the worker in the lists of critical factors of the organization, enjoy the property of the importance and the utmost necessity, and to have a significant impact on the performance of the organization, its work, goals, and future.

2. Comprehensiveness: When measuring, applying, and working, it should be comprehensive for all levels of the administrative organization, all its activities and operations, all its divisions, units and divisions, and all its employees.

3. Realism: the possibility of applying these factors effectively to the reality of the work of the organization; without limitations, constraints, conditions, or preconditions.

4. Harmonization and Hierarchy: Critical factors have hierarchies that are consistent with the organizational hierarchy of the organization you define and are compatible with the type of goals you seek to achieve, and the decisions that are made to achieve these goals.

\subsubsection{Strategic Planning, Concept, Importance, Pillars}

Strategic planning is defined as "the science through which long-term organizational goals are determined, the selection of means (strategies and policies), and the allocation of resources and the development of long-term plans to achieve the goals"[3]. Accordingly, strategic planning deals with the opportunities and threats that the future is expected to carry, as well as what the reality of the organization can be based on the decisions that will be taken by its management, Hence the importance of strategic planning is the basis of the administrative process, and its importance is through the following: [4], [5], [6]. Distinguishes the organization from its competitors by its ability to anticipate events by anticipating and predicting its future and preparing for this future.

1. Strategic planning helps to determine the direction that the Organization should take, and set realistic goals in line with the vision and mission set for it.

2. Strategic plans are a roadmap that enables management to align its functional activities with the objectives it seeks to achieve, as well as identify the right directions to search for the right data and information and adopt them in making and making the right decisions.

3. The Organization's market share and profitability can be increased through a specialized and well-planned strategic plan. By obtaining valuable statistical data on market trends and market categories, the organization's marketing efforts and capacities can be directed towards achieving the best results by increasing its sales and market share.

4. Strategic planning ensures the continuity of the organization and the continuation of its work in the near and long term, specifically with all the variables that surround it, which impose great constraints and challenges restricting its movement.

In the light of the foregoing, we believe that strategic planning is of great importance to business organizations, and in order to achieve the benefits that accrue from these plans, the process of building and formulating strategic plans should be based on a set of pillars, which contribute to the construction of solid plans, strong, enabling the organization to achieve the highest returns. These anchors are as follows: [7]. 
1. Diagnose the target market groups with the organization's operations and activities.

2. To formulate a clear message for the organization, with an accurate statement of its mission, the reasons for its existence, and its objectives that aim to reach it.

3. Good and correct understanding of the strengths and weaknesses of the organization, as well as the opportunities it can have and the threats it may face in the market.

4. To see the future management of the organization on its location and reality that it wishes to achieve.

5. Identify the executive and procedural mechanisms that will enable the organization to reach the future it wishes to be.

\subsubsection{The Stages of Strategic Planning:}

Strategic planning is a series of episodes that are built and based on a set of data and indicators that are studied and analyzed to make the best and most appropriate strategic decisions for the future of the organization. These stages can be summarized as follows: [8], [9], [10]

A. Planning Preparation Phase: At this stage, strategic planning is carried out through the following:

1. Identify the task force that will take over the tasks and responsibilities of strategic planning.

2. The reasons for resorting to strategic planning.

3. How long it will take to prepare the plans, and how long these plans will cover.

4. Determine the method, method, work mechanisms, research, study, and analysis of the data and information that will be used during the preparation of the plan.

5. Develop a scheduled program setting out meetings and meetings to be held on the sidelines of activities related to the preparation of the plan.

Monitor the necessary funds that support the preparation of strategic plans. Analysis of the current reality of the organization: This stage has its importance and its great impact in building plans, as it should identify the internal environment of the organization, and work to analyze it and identify the strengths and weaknesses, as well as the external environment in which the organization operates and affect, and what opportunities can be The environment provides the organization with which it can generate revenues and revenues, as well as the expected threats that the organization may face, and the coping mechanisms it requires.

Identify the vision, mission, and values of the organization, which are essential to be translated through strategic plans, each of which refers to the following:

* Vision of the Organization: A point to which the organization aims its activities and operations, which translates the image that it would like to be in the minds of its customers.

* The mission of the organization: phrases that explain and explain why the organization exists, and what characteristics and attributes that make it unique and distinct from its competing organizations that exist in the same market.

* Values of the organization: standards, ethical and cultural controls agreed upon by the organization, and adhered to by all employees at all levels of the organization.

B. Determining the orientation of the organization and its strategic objectives: Here, it is determined what the organization aspires to, and the direction it will adopt in its work, which can be clarified as follows:

* Strategic orientation: options adopted by the management of the organization, to enable it to determine its future direction, in order to achieve its mission. 
* Goal Setting: In accordance with the organization's strategic directions, it defines objectives that should be clear, programmed, specific, realistic, actionable, and consistent with the reality of the organization.

C. Formulation of the Plan of Action: The concept of the Plan refers to the road map to be adopted by the Organization to achieve its objectives through the following:

1. Determine the objectives and the results achieved from each of them.

2. Identify activities that are consistent with each outcome.

3. Identify the programs, activities, and processes necessary to achieve the objectives.

4. Determine the criteria that will be adopted to measure activities, their results, objectives, and the extent to which they have been achieved, indicating the source of these standards and the degree of their reliability.

5. Determine the human and material resources and allocate sufficient funds necessary to achieve the objectives.

6. Schedule work steps promptly, following the stages required to implement activities and operations and achieve the objectives.

7. Distribution of tasks, identifying individuals who will accomplish the achievement, with sufficient powers to take appropriate decisions that are consistent with the task, and the size of the authority they have.

Follow-up and evaluation of implementation: Through follow-up, the decision-maker can get a clear picture of how the organization works and compare it with what has been planned.

\subsubsection{Critical Strategic Planning Factors}

The management of the organization seeks to diagnose critical factors with a high impact that its goals and objectives can reach, and give these factors the importance and care they deserve, and work to employ them in a manner that achieves them positive and satisfactory results for them and the beneficiaries of their products, and these factors include according to each of [11], [12], [13].

A. Strategic orientation: It represents the approach to be adopted by the organization and determines the movement, and builds a vision of the future image in the mind of the customer. The importance of defining the strategic direction of the organization lies in its benefits which are reflected in the performance of the organization and its ability to achieve its goals effectively, which can be summarized as follows: [14]

1. The concentration of the Organization in activities and processes related to the strategic impact of the Organization's performance.

2. Enable managers to develop a strategic vision on the status of the organization.

3. Understand the rapid environmental change movement and its impact on the organization.

4. Building actionable strategies that translate the goals and objectives of the organization.

5. Developing the work of the Organization and improving performance in the short and long term.

6. Developing habits of future thinking, anticipating the future status of the organization. 7.

B. Strategic Thinking: The method adopted by the management of the organization in analyzing and studying the challenges and factors facing it, and how to deal with them. Strategic thinking is important for business organizations in general, and this importance is reflected in the following: [15]

1. Arrange and diagnose the priorities of the organization. 
2. Empowering the employees of the organization, especially those in the senior management to penetrate the future.

3. Clarity of the strategic vision of the organization what its future will be.

4. Reducing uncertainty, and reducing the level of risk.

5. Rational use of the organization's resources.

C. Strategic Analysis: The set of elements adopted by the organization in the analysis of its internal and external environment variables. Strategic analysis has its importance, which is highlighted through the following:

1. Diagnosing the elements of the internal and external environment of business organizations.

2. Reducing environmental uncertainty and reducing the levels of risk the Organization is expected to face.

3. To identify future opportunities looming on the horizon of the Organization.

4. Know the competing organizations that could pose a threat to the organization and its products, and reduce the customer's market share.

5. Anticipate what the future of the organization will be, and form a picture of what that future shape will look like, and the location of the organization.

6. Highlighting the competitive advantages of business organizations and employing them in starting towards entrepreneurship.

7. The starting point of the organization towards development, renewal, and change in accordance with the need of the renewable and changing market.

D. Strategic flexibility: represents the ability of the organization to respond to environmental changes that can occur at the internal and external levels, and adapt to their challenges, specifically in periods when the environmental vision is blurred and unclear. Strategic flexibility is important for all business organizations through the following:[16]

1. A smooth transition between more than one strategic alternative can achieve the organization with the same objectives.

2. Initiating change through the Organization's competitive advantages.

3. Proactive capabilities that enable it to analyze the internal and external environment of the organization, and thus take advantage of the looming opportunities for additional returns, the number of risks associated with these opportunities, and how to manage these risks.

4. Improving the level of performance and moving from traditional to the creative performance that enables the organization to offer new products.

5. Restructuring the organization in accordance with the goals and new environmental changes.

6- Enabling the organization to display its products in more than one market, and creating greater value for the customer.

\subsection{Marketing Excellence}

\subsubsection{Marketing Excellence, Concept and Importance}

Marketing excellence is defined as "exploring and exploiting marketing opportunities that ensure the long-term success of an organization" [17] and is defined as "a dynamic, dynamic ability of an organization to achieve superior performance through Balanced utilization of their current resources and exploring future capabilities in marketing activities"[18]. 
Marketing excellence is so important and can be recognized by business organizations through the following:[19]

1. Balance the Organization's exploration capabilities and exploit opportunities in a changing environment.

2. Compatibility between the current and future resources of the organization and the requirements for exploring and exploiting opportunities.

3. Adopting a future perspective that anticipates the events that occur and prepares the organization to accept the changes and the trade-off between what can be achieved in the future.

4. Requiring the leadership of the organization to deal with the amount of information that may be sometimes conflicting and contradictory.

5. To create a higher value for the organization and its products in the near and long term, with the development of marketing.

6. Adopting creativity as an approach to enable the organization to adapt to new requirements that may impose on the organization to enter new markets.

\subsubsection{The attributes of marketing excellence}

Marketing excellence has its own characteristics that can be indicated business organizations, and these indicators are:[20]

A. Recognize Marketing Opportunities: represents the ability of the organization to identify the factors and variables that surround the organization, and diagnose opportunities looming in the future prospects, and the threats that may face negatively reflected, as well as the mechanisms that will be adopted in achieving the balance between them in the light of environmental determinants.

B. Seize marketing opportunities: It is a benefit of material or moral value to benefit the organization, as it is one of the means to achieve the goals, which, if well-exploited, enabled them to achieve high returns.

C.Organizational flexibility: This shows the ability of the organization to reshape itself and adapt to market variables that are at the same time a strategic competitive advantage.

\subsubsection{Dimensions of Marketing Prowess}

Marketing excellence has based a set of dimensions that the organization uses in marketing to ensure its versatility and distinction in the market. These dimensions are as follows:[21]

Exploring opportunities: a series of steps leading to innovation in introducing new products, improvements in existing products in the market, improving existing production processes, or designing new production processes that enable them not only to provide products that meet the customer's needs, but enable the organization to enter new markets, gaining new customers, and adopting new distribution outlets.

1. The exploitation of opportunities: The ability of the organization to manage the variables that have generated new marketing opportunities, and improve activities and processes to create value in the near term, by providing the requirements of customers in the current markets, and expand both knowledge and skills, products, services, and distribution channels.

2. Marketing flexibility: Demonstrates the ability of the organization to adapt, and adapt to change, imposed by forces beyond its control, coming from its external environment, 
which obliges the organization to make new changes in existing products, or to provide new products that meet the desire of the customer and provide him in time, And the right place.

3. The Field Framework: This research is concerned with the presentation of the field results and analysis after conducting statistical treatments and draw conclusions that determine the possibility of accepting or rejecting the hypotheses of the study, through the following:

\section{A. Proof of the validity of the first main hypothesis and the hypotheses derived therefrom}

For the purpose of testing the hypothesis of the first major study, which assumes a significant correlation between the main variable represented by the critical strategic planning factors at the macro level and the adopted variable represented by marketing prowess. A significant correlation between the critical strategic planning factors at the macro level and by combining their dimensions with marketing prowess. Between critical strategic planning factors at the macro level and marketing ingenuity. These findings support the validity of the first major hypothesis, which states that "critical strategic planning factors at the macro level are significantly related to marketing excellence. In order to reach indicators indicating the nature of the relationship between each of the critical strategic planning factors and marketing excellence, the correlation was analyzed according to the following:

Table 1. The relationship between the critical strategic planning factors at the macro level and marketing

\begin{tabular}{|c|c|c|c|}
\hline \multicolumn{2}{|c|}{ Values $\alpha$} & $\begin{array}{c}\text { Critical strategic planning } \\
\text { factors }\end{array}$ & Independent variable \\
\hline The specific & Calculated & & Supported variable \\
\hline 0.01 & 0.000 & 0.78 & Marketing prowess \\
\hline
\end{tabular}

Source: Prepared by researchers based on SPSS results $(\mathrm{N}=43)$

1. Strategic orientation: According to the results shown in Table (2), the strategic orientation is positively correlated with the marketing excellence of the researched companies group, where the degree of correlation reached (0.76) and the level of significance (0.000) less than the value $(\alpha)$ determined by $(0.01)$ The reliability score $(0.99)$, which shows the availability of positive statistical indications about the relationship between strategic direction and marketing excellence, which indicates the high interest paid by the management of the research group in building a perception of what its future image will be in the market, and what requirements should A condom is available to make this positive image material, actual, embodied through the group offered products to the customer, and it accepts the first sub-hypothesis which states that "the strategic direction of marketing is linked to moral excellence.

Table 2. The relationship between the critical strategic planning factors at the macro level and marketing excellence

\begin{tabular}{ccccc}
\hline Strategic flexibility & $\begin{array}{c}\text { Strategic } \\
\text { Analysis }\end{array}$ & $\begin{array}{c}\text { Strategic } \\
\text { Thinking }\end{array}$ & Strategic direction & $\begin{array}{c}\text { Independent variable } \\
\text { Supported variable }\end{array}$ \\
\hline 0.71 & 0.79 & 0.78 & 0.76 & Marketing prowess \\
\hline
\end{tabular}

Source: Prepared by researchers based on the results of the program (SPSS) $\mathrm{N}=43$ 
2. Strategic Thinking: The results of Table (2) show a positive correlation between strategic thinking and marketing excellence in the group of research companies, where the degree of correlation (0.78), at the level of significance (0.001), which will certainly be less than the value set for $(\alpha)$ of $(0.01)$, at the level of reliability (0.99), which confirms the adoption of the respondent's mechanisms to enable them to study and analyze all the factors and challenges that may face them in the work environment, with the development of mechanisms that enable them to deal with and employ them in a way that enables the group not only Survival in the market and even growth and continuity and development in it too. Accordingly, it accepts the second sub-hypothesis, which states that "strategic thinking is linked morally to marketing excellence. 3. Strategic Analysis: The results of Table (2) indicate that the degree of correlation between strategic analysis and marketing excellence was (0.79), and that the value of the statistical test $(\alpha)$ extracted (0.000) was low, compared with the specified ones of $(0.01)$, Thus, it can be clearly inferred to the positive moral relationship between the strategic analysis and marketing excellence, and therefore accept the third hypothesis, which states that "strategic analysis is significantly related to marketing excellence.

4. Strategic flexibility: The data of Table (2) confirm the correlation of strategic flexibility with marketing excellence, as the data indicate that the correlation between them has reached $(0.71)$, and that the value $(\alpha)$ was low, which is less than the value specified $(0.01)$, at The level of reliability (0.99), which emphasizes the moral correlation of strategic flexibility with marketing excellence, and therefore accepts the fourth sub-hypothesis, which states that "strategic flexibility is correlated with marketing excellence". Achieve the highest benefit Possible of them, and to serve the objectives of the group of companies and their objectives. Based on the above results of the linkages between the critical strategic planning factors and marketing excellence, the first main hypothesis and its sub-hypotheses are accepted.

B. Proof of the validity of the second main hypothesis and the hypotheses derived therefrom

Simple linear regression results will be used to diagnose the impact relationship between critical strategic planning factors and marketing prowess. According to the data of Table (3), the value of $(\mathrm{F})$ calculated to test the impact of critical strategic planning factors at the macro level in marketing prowess (25.125), which is high when compared with the level of significance (Sig.F) of (0.000), and accordingly affect Critical strategic planning factors at the macro level in marketing excellence, and for the purpose of validating this result, we find that the change of one unit in the strategic planning factors leads to a change (0.535) in marketing excellence.

Table 3. The Influential Relationship between Strategic Planning Factors at the Macro Level and Marketing Proficiency

\begin{tabular}{|c|c|c|c|c|c|c|}
\hline $\begin{array}{c}\mathrm{R}^{2} \\
\text { Modified }\end{array}$ & $\begin{array}{c}\text { Coefficient of } \\
\text { interpretation } \\
\mathrm{R}^{2}\end{array}$ & Sig.F & Calculated & $\begin{array}{c}\text { Critical } \\
\text { strategic } \\
\text { planning } \\
\text { factors } \\
\text { B1 }\end{array}$ & $\begin{array}{c}\text { Constant } \\
\text { A } \\
\end{array}$ & $\begin{array}{c}\text { Independent } \\
\text { variable } \\
\text { Supported } \\
\text { variable } \\
\end{array}$ \\
\hline 0.600 & 0.615 & 0.000 & 25.125 & 0.535 & 1.690 & $\begin{array}{l}\text { Marketing } \\
\text { prowess }\end{array}$ \\
\hline
\end{tabular}

Source: Prepared by researchers based on SPSS results. 
The value of the explanation coefficient (R2) was to support the impact relationship, because through the coefficient of interpretation (R2), the critical strategic planning factors at the macro level have succeeded in the interpretation $(61 \%)$ of the total changes in marketing prowess, and the rest is due to variables Other factors have not been addressed, indicating a significant influence related to the critical strategic planning factors at the macro level in marketing excellence, and therefore accepts the second key hypothesis, which states that "critical strategic planning factors and the macro-level have a significant effect on marketing excellence. To demonstrate the type of relationship between each critical strategic planning factor and marketing excellence, the impact relations between the independent and approved variable was analyzed as follows:

1. Strategic direction: The results of table (4) show that the value of (F) calculated to measure the impact of strategic direction in marketing prowess was (19.026), and compared with the level of significance (Sig.F) of (0.000), and according to each of the orientation Strategic and marketing excellence with an impact relationship, and to confirm this note that the change of one unit of strategic direction leads to positive changes in marketing excellence by $(0.507)$. The explanation coefficient (R2) shows that the strategic orientation explains the changes in marketing prowess by $(58 \%)$, which emphasizes the importance of the strategic orientation and its obvious impact on marketing prowess, and the rest of it is due to other factors not included and studied, and therefore accept the sub-hypothesis The first emerges from the second main hypothesis, which states that "strategic direction has a significant effect on marketing prowess."

Table 4. The Influential Relationship between Strategic Direction Factors and Marketing Proficiency

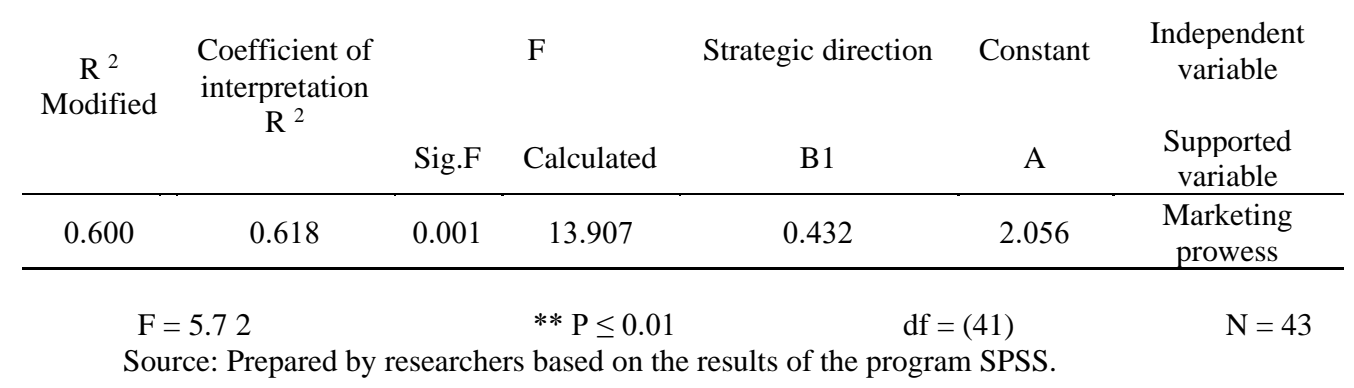

2. Strategic Thinking: The results of Table (5) indicate that the value of the statistical test (F) to measure the impact of strategic thinking in marketing excellence, reached (13.907), which is higher than compared with the level of significance (Sig.F) of (0.001), this result indicates that there are significant effects of strategic thinking in marketing excellence. These data confirm that strategic thinking is explained by the value of the explanation coefficient (R2) the value of $(61 \%)$ of the changes in marketing excellence, and the completion of this ratio is due to other factors not Addressing it, he accepts the second sub-hypothesis, which states, ACR moral excellence in marketing. 
Table 5. The Influential Relationship between Strategic Thinking and Marketing Proficiency

\begin{tabular}{ccccccc}
$\mathrm{R}^{2}$ & & $\mathrm{~F}$ & Strategic Thinking & Constant & $\begin{array}{c}\text { Independent } \\
\text { variable }\end{array}$ \\
Modified & $\begin{array}{c}\text { interpretation } \\
\mathrm{R}^{2}\end{array}$ & Sig.F & Calculated & $\mathrm{B} 1$ & $\mathrm{~A}$ & $\begin{array}{c}\text { Supported } \\
\text { variable }\end{array}$ \\
\hline 0.600 & 0.618 & 0.001 & 13.907 & 0.432 & 2.056 & $\begin{array}{c}\text { Marketing } \\
\text { prowess }\end{array}$ \\
\hline $\mathrm{F}=5.72$ & & $* * \mathrm{P} \leq 0.01$ & $\mathrm{df}=(41)$ & & $\mathrm{N}=43$
\end{tabular}

Source: Prepared by researchers based on the results of the program SPSS.

3. Strategic Analysis: The value of (F) calculated to measure the degree of influence of strategic analysis in marketing excellence according to the data table (11) (15.410), which confirms the relationship of positive impact between them when comparing the value of $(\mathrm{F})$ calculated with the level of significance (Sig.F) This result confirms that the change of one unit of strategic analysis leads to a change in marketing prowess by (33\%). The strategic analysis has the ability to explain (62\%) of the changes in marketing excellence. Accordingly, it accepts the third subhypothesis, which states that "strategic analysis has a significant effect on marketing prowess".

Table 6. The Influential Relationship between Strategic Analysis and Marketing Proficiency

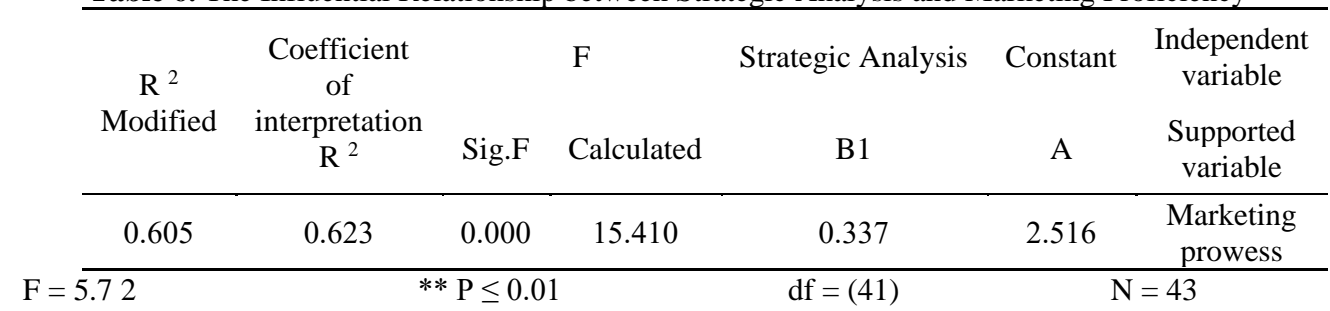

Source: Prepared by researchers based on the results of the program SPSS.

4. Strategic flexibility: The data of the results of table (7) indicate that the value of $(F)$ calculated to measure the impact of strategic flexibility in marketing prowess was (15.137), and greater than the level of significance (Sig.F) of (0.000), and accordingly affect flexibility Strategy in marketing prowess, as the change of one unit of strategic flexibility causes a change in marketing prowess by (0.332). The coefficient of interpretation (R2) refers to the ability of strategic flexibility in the interpretation of the amount of $(50 \%)$ of the changes in marketing prowess, complementing this value is due to other factors not addressed in the study and analysis in this model. It accepts the fourth sub-hypothesis, which states that "strategic flexibility significantly affects marketing prowess". 
Table 7. The Influential Relationship between Strategic Flexibility and Marketing Proficienc.

\begin{tabular}{|c|c|c|c|c|c|c|}
\hline $\begin{array}{c}\mathrm{R}^{2} \\
\text { Modified }\end{array}$ & $\begin{array}{c}\text { Coefficient of } \\
\text { interpretation } \\
\mathrm{R}^{2}\end{array}$ & Sig.F & Calculated & Flexibility Strategic of & Constant & $\begin{array}{c}\text { Independent } \\
\text { variable } \\
\text { Supported variable }\end{array}$ \\
\hline 0.485 & 0.503 & 0.000 & 15.137 & 0.322 & 2.529 & $\begin{array}{c}\text { Marketing } \\
\text { prowess }\end{array}$ \\
\hline
\end{tabular}

Source: Prepared by researchers based on the results of the program SPSS.

Based on the above, the second main hypothesis and its sub-hypotheses have been established, which indicate the positive influential relationships that link the critical strategic planning factors at the macro and sub-levels with the marketing excellence of the research group.

\section{Conclusions and Recommendations}

\subsection{Conclusions}

This paragraph reviews a number of conclusions of the study, as follows:

1. Critical factors represent important areas and conditions for achieving the objectives of the organization, and therefore the management attaches great importance to the organization.

2. Critical factors vary from organization to organization, and their importance varies according to time periods.

3. Strategic planning outlines the future of the Organization, including goals, objectives, mechanisms, procedures, and policies adopted to achieve these goals and achieve the goals.

4. Marketing excellence means that the organization has exceeded the threshold of success to reach the peak of marketing work in the light of complex factors and challenges.

5. The results of the descriptive analysis of the two dimensions of the study showed the focus of the respondents' responses in a positive direction, which indicates the contribution of critical strategic planning factors in enhancing the marketing excellence of the group of companies. 6. Statistical results showed the positive significant correlation of the critical strategic planning factors combined on the macro, and the level of factors (strategic direction, strategic thinking, strategic thinking, and strategic flexibility) with marketing excellence in the group of companies researched.

7. Statistical results indicated a positive correlation effect of the critical strategic planning factors combined on the macro, and the level of factors (strategic direction, strategic thinking, strategic thinking, and strategic flexibility) marketing excellence in the group of companies researched.

\subsection{The Recommendations}

1. Continuous evaluation and examination to identify critical factors of paramount importance to the organization. 
2. Arrange critical strategic planning factors according to the degree of their importance and their impact on achieving the objectives.

3. Focus on the most critical factors affecting the present and future of the research group, with a continuous assessment of these factors and study new developments and developments and employ them to enhance marketing excellence.

4. Given the existence of a correlation and significant impact of the wave of strategic factors at the macro and individual levels of each of these factors, and the reflection of these relations in the ingenuity of the research group, it is necessary to give the management of the research group sufficient importance, with the need to use these relationships in the formulation of objectives And build plans to achieve them.

5. Focus on marketing excellence being the tool of the organization to maintain the position achieved by the group in a competitive market.

6. Marketing excellence immunity of the research group and must be strengthened continuously as being vulnerable to developments and changes that can occur in the business environment.

7. Achieving marketing prowess opens up new areas for the group to promote marketing to more advanced ranks than competitors.

\section{References}

[1]Marais, M., De Plessis, A. and Melville, S.: A Review of Critical Success Factors in Tourism, Vol. 31, No. 3, Journal of Hospitality and Tourism Management, (2017).

[2] Amdy, B., Obani, E. C., Umagh, E., Eugene-Mario and Njoko, U., Anita P.: Critical Success Factors in Delivering a Public Sector Establishment Project: The Case of Owerri, Imo State, Vol. 3, No. 1, International Journal of Research in Management, Science and Technology, (2015).

[3] Al-Khafaji, N.A.: Strategic Management, Dar Al-Thaqafa for Publishing and Distribution, First Edition, Amman, Jordan, (2004).

[4]Morsi, N.M.: Strategic Management, New University House, Alexandria, Egypt, (2003).

[5]Talant, J.: The Importance of Strategic Planning in the Business Environment, GRIN Verlag, Munich. https://www.grin.com, (2009).

[6] Del Peru, M., The Importance of Strategic Planning, Vol. 57, number 2, Journal of Reinforced Plastics, (2013).

[7] Wolf, C., and Floyd, S.W.: Strategic Planning Research: Towards a Theory-Driven Agenda, Vol. 43, number. 6, Journal of Management, (2013).

[8]Grover, V., and Segars, A.H.: An Empirical Assessment of Strategic Information Systems Planning Stages: Process and Effective Design Patterns, Vol. 42, No. 5, July, Journal of Information and Management, Information and Management, (2005).

[9]Al-Shobaki, M.J. Yousaf, Ammouna, A. and Sami Nasser, S. A.: The Impact of Higher Management Support for Strategic Planning in Crisis Management: A Case Study on UNRWA - Gaza Strip, International Journal Research and Academic Development 1 (10), (2016).

[10]Hubner, A., Heinrich K., and Johannes, F.: Mileni's latest distribution and distribution in the Omnichannel: Planning Planning Framework, vol. 44, No. 3 International Journal of Retail and Distribution Management, (2016).

[11]Camilleri, E.: Success Project Critical Factors and Behaviors, Taylor \& Francis Group, LLC, Florida, (2016).

[12]Haines, S.: Systems Thinking Approach in Strategic Planning and Management, Taylor \& Francis Group, LLC, Florida, (2016).

[13]El-Banna, S., Andrews, R., and Riley B.: Strategic Planning and Successful Implementation in Public Service Organizations: A Guide from Canada, , Vol. 18, Issue. 7 Journal of Public Administration, (2016). [14]Makrash, F.: the Impact of Intelligence Management on the Strategic Direction of the Corporation: Case Study of Air Algerie, Unpublished Ph.D. Thesis, Faculty of Economic, Commercial and Facilitation Sciences, Mohamed Khedr University, Biskra, Algeria, (2015). 
[15]Helbawi, K.: strategic thinking, Dar Kalima, Mansoura, Egypt, (2004).

[16]Ahmed, A.: the impact of strategic flexibility on the quality of performance efficiency and competitiveness of the institution: an applied study on Mobiles Telecom, unpublished doctoral thesis, Faculty of Economic and Commercial Sciences and Facilitation Sciences, University Jilali Yabis Sidi Bel Abbes, Algeria, (2017)

[17]Wei, X., Chow, J., Zhang, C.: Organizational Skill, Market Orientation, Steady Performance, N0.33, Journal of Engineering and Technology Management, (2014).

[18]Josephson, B.W., Johnson, J., Maryadus, L., Babu J.: Strategic Marketing, Dexterity: Precedents and Financial Results, Vol. 44, No. 4, July, Journal of the Academy of Marketing Science, (2016).

[19]Tokgoz, E., Akatay, A., Ozdemir, S.: The Impact of Funny Marketing on the Market and Financial Performance, Proceedings of the EBEEC Conference, Balkan and Eastern European Economies in the Changing World, KnE Social Sciences, (2017).

[20]Prang, C., Schlemmelmech, B.b.: The role of oversight in the implementation of marketing strategy: solving the problem of exploration and exploitation, Vol. 2, No. 2. December 2009, pp. 215-240, Journal of Business Research, (2009).

[21]Al-Musawi, K., Hameed H.: Strategic Agility and its Role in Achieving Marketing Proficiency: An Analytical Study of the Opinions of a Sample of Managers in Al-Kafeel Company, Journal of Arts of Kufa, (2009). 